\title{
Artistas y espacio urbano: la representación de la ciudad en el arte contemporáneo
}

\author{
Miguel Ángel Chaves Martín \\ Universidad Complutense de Madrid \\ machaves@ucm.es
}

\begin{abstract}
Resumen:
En la construcción de la imagen de la ciudad moderna, junto al arte público juega también un papel fundamental el ámbito de las representaciones de la ciudad, tanto en la pintura como en la fotografía o la ilustración gráfica. Estas miradas cruzadas al paisaje urbano, críticas o creativas, objetivas o imaginadas, revelan las contradicciones propias de la ciudad moderna, sus valores y significados, a la vez que condicionan la apreciación que de las mismas tienen los ciudadanos que, convertidos en espectadores, analizan y ven la ciudad a partir de sus imágenes plásticas.
\end{abstract}

Palabras clave: paisaje urbano; ciudad contemporánea; iconografía de la ciudad; artes plásticas; representación.

Artists and urban space: the representation of the city in contemporary art

\begin{abstract}
:
In this construction of the image of the modern city, besides the public art will, it also play an important role the area of representations of the city, both in painting and photography or graphic illustration. These differing viewpoints to the cityscapes, critical or creative, objective or perceived, reveal the contradictions of the modern city, their values, meanings, at the time that have an influence on the appreciation of the citizens as spectators have of them, who analyzed and see the city from its plastic images.
\end{abstract}

Key Words: urban landscape; contemporary city; iconography of the city; arts; representation.

\section{Referencia normalizada:}

Chavez Martín, M. A. (2014): Artistas y espacio urbano: la representación de la ciudad en el arte contemporáneo. Historia y Comunicación Social. Vol. 19. Núm. Especial Marzo. Págs. 277-288.

Sumario: 1. Introducción. 2. Metodología. 3. Convergencias: artistas, arte público, instituciones culturales y espacio urbano. 4. Imágenes: la mirada del artista. 5. Conclusión. 6. Referencias bibliográficas. 


\section{Introducción ${ }^{1}$}

Durante los siglos XIX y XX, en un proceso constante pero de desigual desarrollo en el tiempo, las ciudades van consolidando su forma urbana como espacios de la modernidad, convirtiéndose desde su gestación en referencia continua para los artistas que supieron leer en ellas las distintas concepciones de lo moderno, hasta hacerlas generadoras de sus visiones, de sus anhelos y también de sus rechazos. Los artistas empezaron a interesarse por representar la ciudad no ya solo como espacio escenográfico en el que acontece algo, sino como objeto en sí mismo, ampliando además el ámbito de la pintura o la ilustración a las nuevas manifestaciones artísticas como el cine o la fotografía. Pero sin olvidar que con anterioridad a este nuevo protagonismo de lo urbano en la mirada de los artistas, la ciudad ya venía siendo representada con un carácter técnico, objetivo, por parte de arquitectos y urbanistas que planificaban los espacios y cartografiaban esa realidad como imagen de la misma.

La representación de la ciudad, entendida aquella como "figura, imagen o idea que sustituye a la realidad" (DRAE, 2001, 22 ed., $3^{\mathrm{a}}$ acepción) es un hecho que corre paralelo a la creación de los espacios urbanos en los que el individuo se asienta, como autoafirmación de lo creado. Representamos nuestro entorno, lo percibimos y recreamos, estableciendo nuevos mensajes y significados a partir de representaciones reales pero también recreadas, imaginadas, interpretadas subjetivamente a través de la mirada de los artistas, que se sienten seducidos por los espacios de la ciudad. Aunque las ciudades siempre han sido importantes focos de irradiación cultural y artística, es con la modernidad cuando el marco urbano se convierte en el centro indiscutible de la creación, pudiéndose hablar entonces, como un elemento más del engranaje cultural, de la creación incluso de barrios artísticos donde confluyen un número importante de artistas y talleres, una presencia notable de arte público y una profusión de establecimientos e instituciones culturales de todo tipo.

Los artistas pondrán de manifiesto con estas representaciones su importante papel en la invención de una cultura moderna de las ciudades. Estas miradas al paisaje urbano, a los nuevos espacios de la cultura y el arte, ya sean objetivas o imaginadas, revelarán las contradicciones de la ciudad moderna, sus valores y significados, condicionando también la apreciación que de ellas y sus espacios tienen los ciudadanos que, convertidos en espectadores, analizan y ven la ciudad a partir de sus imágenes plásticas. El resultado es un proceso más amplio y complejo de construcción de la imagen urbana que afecta notablemente a la imagen de los barrios artísticos, tanto en su configuración inicial como en su posterior desarrollo, transformación y uso, con destrucciones, renovaciones, cambios morfológicos y creación de nuevos iconos.

\section{Metodología}

El presente trabajo defiende una visión diacrónica del arte contemporáneo, utilizando las imágenes generadas por las obras de los artistas plásticos como eje verte- 
brador de los análisis urbanos, arquitectónicos, artísticos, patrimoniales y sociales que los caracterizan en su contexto espacial y temporal. Herramienta fundamental de análisis es el método iconográfico/iconológico desarrollado por Panofsky y Warburg, y continuado por Saxl y Gombrich entre otros autores, integrándolo en una concepción metodológica más amplia en la que convergen aspectos sociológicos, formales, estructurales, psicológicos, etc. Esta necesaria convergencia metodológica se apoya en una idea de ciudad amplia, entendida como un complejo de relaciones sociales, económicas, demográficas, artísticas, culturales y políticas que se desarrollan en un entorno urbano. En consecuencia, la ciudad no sólo es un objeto de uso colectivo sino también el resultado de la convergencia de todas las técnicas artísticas que dan lugar a la formación de un ambiente tanto más vital cuanto más rico en valores artísticos (Argan, 1984: 63).

En una sociedad eminentemente urbana como la actual, esta consideración de partida nos lleva a la necesidad de desarrollar estudios relacionales entre arte, ciudad y comunicación en línea con lo planteado por García Canclini y Martín Barbero (1994: 23) desde la comprensión de la ciudad como entidad que alberga diversidad de grupos sociales, como lugar en permanente adecuación a los requerimientos sociales, conduciendo inevitablemente al reconocimiento de lo comunicacional. De la misma manera que los procesos comunicacionales atraviesan las actividades sociales, la comunicación subyace en la base de los productos construidos por el hombre, asentándose en las urbes donde se congregan los puntos centrales de la comunicación social.

\section{Convergencias: artistas, arte público, instituciones culturales y espacio urbano}

En el año 2001 una exposición comisariada por Iwona Blazwick en la Tate Modern de Londres (Century City. Art and Culture in the Modern Metropolis) culminaba las investigaciones de su equipo en torno a una idea central como era la exploración de las relaciones entre la metrópolis como forma de ciudad contemporánea y la creación artística. Para ello se apoyó en aquellas ciudades pioneras, paradigma de la vanguardia y los movimientos artísticos contemporáneos que, sin duda, han participado notablemente en la construcción de la ciudad y su imagen. El planteamiento de Blazwick apunta a que la cultura visual no aparece y se desarrolla de manera aislada, sino en interacción con la ciudad, con lo social, lo político y lo urbano, extendiendo además sus tentáculos al diseño, al cine, a la danza, la música y la literatura. Para ello tomará como referencia algunas ciudades emblemáticas de los cinco continentes, en diferentes momentos, siempre significativos, de su evolución. En el ámbito europeo centraron la investigación en el Londres del "milenio" (1990-2001), el Moscú vanguardista y revolucionario de 1916-1930, el París de las primeras vanguardias prebélicas (1905-1915) y la Viena revolucionaria de la década 1908-1918. El planteamiento se va a apoyar en la premisa, ya lanzada décadas atrás por Henri Lefebvre, de que la ciudad es un living work of art colectivamente creado por todos sus ciuda- 
danos (políticos, economistas, pintores, diseñadores, cineastas, fotógrafos, etc.), en consonancia con la idea de "arte total" frecuentemente presente en el pensamiento contemporáneo, y de la que se hicieron eco también Giulio Carlo Argan (1984) y Lewis Mumford (1966) al entender la ciudad como una obra de arte.

La colaboración de Sharon Zukin en el proyecto británico abrió el mismo hacia uno de los temas esenciales de toda la contemporaneidad y especialmente significativo en las últimas décadas: la creación de barrios de artistas, los talleres de artista, y la presencia de galerías y museos en los centros urbanos como "regeneradores" de los espacios ciudadanos, de los que se han ocupado Zukin (1982, 1988, 1995 y 2001) en el ámbito anglosajón, y Jesús Pedro Lorente (1997 y 1998) y Ángeles Layuno (2003 y 2004) en el caso español. Es precisamente esta última autora quien analiza las consecuencias que sobre el museo han tenido los postulados revisionistas del Movimiento Moderno (Aldo van Eyck, Norberg-Schulz, Kevin Lynch), en el sentido de un estrechamiento de vínculos entre el museo y el planteamiento urbano que se traduce tanto a nivel físico (reestructurante) como a nivel semántico (monumento-símbolo).

La dimensión urbana del museo entraña, así, una pluralidad de efectos del hecho arquitectónico sobre el contexto en que se emplaza. En los últimos tiempos, los museos o centros de arte contemporáneo son considerados piezas motoras de los planes y proyectos urbanísticos de rehabilitación sectorial e integral de áreas de la ciudad histórica, debido a los poderes que se les adjudican, no sólo reestructurantes del tejido urbano, sino también socioeconómicos y simbólicos; es decir, como instrumentos excelentes para la proyección de una imagen monumental expresiva del poder de las ciudades y sus gobernantes. Pero además, el proyecto arquitectónico engloba a menudo una dimensión urbana per se, incluyendo tanto en sus límites como en su interior espacios de carácter cívico, urbano o semiurbano, produciéndose una apropiación de tipologías y funciones procedentes de ámbitos de convivencia externos, ahora interiorizados y domesticados en relación a fenómenos culturales masivos.

Por otro lado, la trascendencia a ser meramente una "máquina expositiva" determina situaciones en que el museo como edificio se convierte en objeto de contemplación estética del escenario de la ciudad o, a la inversa, la ciudad se piensa como objeto estético o conceptual captado visualmente desde el museo. Con todo ello, las investigaciones de Ángeles Layuno sugieren la idea de museo como objeto arquitectónico poroso, interactuante respecto a su entorno. En este punto es preciso señalar los diferentes elementos que entran en juego en los límites del museo, entendiendo en este caso el concepto de límite tanto en su acepción epidérmica o física como funcional.

Ampliando el abanico cronológico hasta el año 1870, pero limitando el estudio a las diferentes propuestas urbanas que se han venido sucediendo en Europa con su correspondiente paralelo plástico, centrado en las imágenes que pintores y fotógrafos han ido plasmando en la construcción de la imagen de la ciudad europea, el trabajo de Alan Guiheux y Jean Dethier (1994) se convierte en la referencia esencial de la que parte esta investigación. En la línea de las publicaciones de L'art et la ville de 
los años 1990 y 1995, el planteamiento de Guiheux y Dethier se apoya en la doble mirada que artistas y arquitectos han tenido sobre la ciudad. Evidentemente, unos y otros no poseen la misma conciencia de ciudad ni, en su opinión, la misma responsabilidad en relación a ella. Los primeros, mucho más que los segundos, se encaran a la dura materialidad de la ciudad y a lo que Baudelaire llamaba su "desesperante fragilidad". Los artistas - argumentan- no tienen ni esta pavorosa responsabilidad, "ni la horrible presunción del que cree que va a levantar ciudades como Dios creó el mundo". La dimensión sensible de su aproximación al tema les impide, por otra parte, considerar la ciudad como un todo, abstracta y completa, fríamente presentada en un plano o en una maqueta. Serán, así, visiones contrapuestas, enfrentadas, bifrontes, de una realidad urbana que puede ser totalmente beneficiosa como representación del progreso y la belleza, o completamente maléfica como representación del caos, la perversión, la fealdad y la indigencia. Una dualidad que, paralela a la configuración de la ciudad contemporánea en los albores del urbanismo como nueva disciplina, ha venido mostrándose hasta nuestros días.

En España han sido los trabajos de Simón Marchán (1986), Juan Antonio Ramírez (1988) y Javier Maderuelo (1992 y 1994) los que con mayor intensidad se han acercado a este planteamiento. El primero se sitúa en las antípodas de la delimitación de las reglas de cada una de las artes y se siente cercano al proyecto moderno, escudriñando la vinculación entre los géneros artísticos, en concreto la relación entre pintura y arquitectura. En su libro Contaminaciones figurativas (1986) Marchán rastrea las interrelaciones existentes entre arquitectura y ciudad con la pintura; asimismo, investiga en las poéticas figurativas, fundamentalmente pictóricas, destacando cómo éstas "informan" ciertas arquitecturas, llegando en su caso a encontrarlas en la "estructura más profunda del organismo arquitectónico". Señala ejemplos de utilización del lenguaje abstracto o reseña la utilización de recursos espaciales, investigados primeramente en el mundo plástico y después asumidos por la imagen y la arquitectura urbana. De su investigación, no exhaustiva pero sí fuertemente sugeridora, surgen líneas que avalan las interrelaciones que de modo general subrayan la imposibilidad de estancamiento en contenedores cerrados a los que tiende a someter la limitación de ciertas orientaciones teóricas que ocultan, en parte, el rico entramado de lo artístico.

Por su parte, Javier Maderuelo se aproxima al tema tanto en sus trabajos en torno a las relaciones entre escultura y espacio urbano (1990 y 1994) como en los Seminarios "Arte y Naturaleza" que organizó en años sucesivos en Huesca desde 1995 y en los que la ciudad aparece considerada como uno de los objetos más recurrentes de las artes en la modernidad. Arquitectura, escultura, pintura, cine y fotografía no sólo han sido - dice- los protagonistas de la construcción de las ciudades sino que han encontrado en los motivos urbanos, en sus escenarios, en sus paisajes y en su dinamismo transformador nuevos temas para sus obras. Las artes, por tanto, han creado y recreado la ciudad como obra de arte y, por otra parte, la ciudad se ha construido como antítesis orgullosa del dominio del hombre sobre la naturaleza. Exposiciones Universales, Vanguardia y Eclecticismo, Abstracción y Geometría... Formas, en definitiva, de aproximarse a la ciudad desde las artes, de recrear la ciudad, de repre- 
sentarla, de construirla, de crear su imagen, al modo en que Toynbee lo entendía: La imagen de la ciudad es como la imagen de los cuerpos, un esquema necesario para radicarse en el mundo.

\section{Imágenes: la mirada del artista}

Representar la ciudad ha sido una realidad que corre paralela al hecho mismo de la creación de los espacios urbanos en los que el individuo se asienta, como autoafirmación, como referente necesario de lo que ha creado. Representamos nuestro entorno, lo percibimos y recreamos, estableciendo nuevos mensajes y significados. La ciudad y sus representaciones, utilizando la expresión de Gorelik (2004: 13), se producen mutuamente. No hay ciudad-seguirá diciendo-sin representación de ella, y las representaciones no sólo decodifican el texto urbano en conocimiento social, sino que inciden en el propio sentido de la transformación material de la ciudad. Esta representación de la ciudad no será únicamente real, cartografiada por urbanistas y arquitectos que la representan técnicamente, sino también recreada, imaginada, interpretada subjetivamente a través de la mirada del artista, del pintor, del fotógrafo o del cineasta. Los jóvenes artistas se sienten rápidamente seducidos por los nuevos espacios de la modernidad, sistemáticamente narrados y representados en sus formas generalmente agitadas, dinámicas, nerviosas, como apuntaría George Simmel ya en los primeros años del siglo XX; pero rápidamente también caerán en el horror, el caos y el rechazo que, una Europa en guerra, les plantea, conduciéndoles a nuevas miradas y huidas de aquellos espacios poco antes idealizados. Se crean así nuevas lecturas de los paisajes urbanos que derivarán en el abanico de trabajos desarrollados en las últimas décadas reivindicando la importancia de los estudios de iconografía de la ciudad.

Pintores, escultores, cineastas, fotógrafos... pondrán de manifiesto con sus obras el papel determinante que han jugado en el proceso de creación e invención de una cultura moderna de las ciudades. De este modo, las miradas cruzadas al paisaje urbano, críticas o creativas, objetivas o imaginadas, revelarán las contradicciones de la ciudad moderna, sus valores y significados, y condicionarán también la apreciación que de las mismas tengan los ciudadanos que, convertidos en espectadores, analizan y ven la ciudad a partir de sus imágenes plásticas.

Esta nueva manera de ver y representar la ciudad coincidirá con el proceso de configuración y desarrollo de la ciudad contemporánea, en el momento en que deja de ser el escenario de cualquier acontecimiento, como había sido habitual en épocas precedentes, para convertirse ella misma en el acontecimiento, en el objeto de la representación. La sugestión por los nuevos espacios de la ciudad, la máquina, el dinamismo, la velocidad, la intensificación de la vida nerviosa como definiera George Simmel a la metrópoli moderna, las periferias industriales, los bulevares, los comercios, el ferrocarril, establecen una nueva relación entre la mirada del artista y el espacio contemplado que, con modificaciones en su apreciación, que irían desde 
la inicial seducción y apego por lo urbano al rechazo y el caos final, se ha mantenido como una constante a lo largo de estos dos últimos siglos.

En el París de mediados del siglo XIX un grupo de jóvenes pintores despectivamente identificados años después como "impresionistas", empezaron a ver la ciudad y sus espacios de una forma radicalmente diferente a como venía siendo habitual en la representación de los paisajes urbanos. Ante su mirada, sobre los bulevares, en las buhardillas de los nuevos inmuebles o en las periferias del Sena, el nuevo París transformado por George Haussmann se convierte en objeto de la representación y no ya en mera escenografía sobre la que acontece algo. El acontecimiento ahora es la propia ciudad, sus calles, su arquitectura, sus ciudadanos. Desde entonces hemos ido viendo crecer y fijar esta idea por medio de diferentes manifestaciones artísticas, entre ellas la fotografía y el cine, que han nacido y se han consolidado como arte a la vez que hemos ido aprendiendo a valorar la ciudad en sus cualidades estéticas.

Mientras que los pintores impresionistas nos dejaban su optimista visión de un París a la medida de la nueva burguesía, otros artistas como Gustave Doré y su serie de grabados London. A Pilgrimage denunciaban la saturación urbana de la metrópoli y la desesperación del proletariado ante sus cada vez peores condiciones de vida. Desde entonces la dualidad de miradas a la ciudad contemporánea ha ido de la mano de artistas como Van Gogh o Pissarro, Munch o Caillebotte, Kandinsky o Boccioni, Kirchner o Grosz, Müller o Beckmann, y tantos otros.

Inicialmente, y pese a las miradas críticas de algunos, la situación generalizada era de asombro y seducción por la nueva belleza de la ciudad contemporánea. Así, en 1908 el artista alemán August Endell publicaba el texto Belleza de la metrópoli, definiéndola como Ese milagro de belleza y poesía; una fábula, la más multiforme y variopinta, nunca narrada por el poeta; una patria, una madre, que colma cotidianamente a sus hijos de alegrías siempre vivas (Pizza, 2002: 181). Es un momento de desbordado entusiasmo e interés por la ciudad, un deslumbramiento ante sus formas, sus espacios, su dinamismo, ante la vitalidad de la vida moderna. Y así el motivo pictórico toma como referencia los nuevos monumentos de la modernidad: frente a las calles tradicionales y los grandes edificios históricos ahora, con el triunfo de la técnica y de la máquina, los motivos de representación son aquellos nuevos iconos, aquellas figuras de la modernidad que están construyendo el paisaje artificial de la ciudad moderna. Así, a las avenidas y bulevares, a las estaciones de ferrocarril y los puentes, se suman también ahora las fábricas, las chimeneas y los suburbios industriales. Y por encima de todos ellos, el icono de la nueva modernidad: la Torre Eiffel que todos los artistas reflejaron, de una u otra manera, en sus obras, desde la mirada naïf de Rousseau a la mirada múltiple y expresiva de Delaunay, el puntillismo de Seurat o las ensoñaciones de Chagall. Es entonces, en 1914, cuando el también pintor Ludwig Meidner publica un breve manifiesto de especial transcendencia con unas Instrucciones para pintar la gran ciudad en el que afirmaba:

Debemos comenzar a pintar el lugar donde hemos nacido, la gran ciudad, a la que amamos con amor infinito. Nuestras manos febriles deberían trazar sobre telas innumerables, grandes como frescos, toda la magnificencia y la extrañeza, toda la 
monstruosidad y lo dramático de las avenidas, estaciones, fábricas y torres. No es posible dominar nuestro problema con la técnica de los impresionistas. Debemos olvidar todos los procedimientos y trucos precedentes y apropiar los medios expresivos completamente nuevos. (...)¡Pintemos lo que está cerca de nosotros, nuestro mundo urbano, las calles tumultuosas, la elegancia de los puentes colgantes de hierro, los gasómetros, que cuelgan entre blancas montañas de nubes, el colorido excitante de los autobuses y de las locomotoras de trenes rápidos, los hilos ondeantes de los teléfonos, las arlequinadas de las columnas publicitarias y por último la noche, la noche de la gran ciudad! El dramatismo de una chimenea de fábrica bien pintada ¿no podría conmovernos más profundamente que todos los rafaelescos incendios del Borgo y las batallas de Constantino? (González, 1999: 117)

De la inicial seducción de la metrópoli a la visión caótica de la misma apenas pasará una década, en la que veremos el cambio entre la Belleza de la metrópoli de Endell y el nuevo pesimismo reflejado en la Metrópolis de George Grosz (Museo Thyssen, Madrid), o la transformación de aquel Meidner que daba instrucciones para pintar la ciudad, por el mismo artista que, en plena guerra mundial, se dedica sistemáticamente a representar el caos y la destrucción de las grandes urbes.

Finalizadas las guerras, superado el período de entreguerras e iniciado el proceso de reconstrucción europea tras 1945, los artistas se van a enfrentar a una ciudad distinta. Las ciudades habían perdido la mirada cotidiana de los impresionistas y la dinámica social de los primeros años de entreguerras. Ahora se impone la fotografía, la pintura hiperrealista y su mirada perdida a espacios muchas veces vacíos como los que representa Richard Estes. Y la antítesis en el rechazo de lo urbano por parte de Wolf Vostel o los Situacionistas. O esconderse en la ciudad, camuflarse dentro de ella para no moverse del sitio, con una clara actitud reivindicativa y de crítica política, como recientemente ha hecho Liu Bolin en su serie Chen shi micai (Oculto en la ciudad, 2005-2013) para criticar precisamente el deterioro, la destrucción y los intereses espúreos que rodean determinados espacios urbanos. Sus camuflajes en Pekín contra la política energética de su país, o en Venecia y Roma criticando el acelerado deterioro de un patrimonio monumental que no puede soportar por más tiempo la masificación y los usos del denominado turismo cultural son buenos exponentes de una serie de trabajos que le han llevado al éxito internacional y con los que, en definitiva, pretende buscar una fórmula para que el público se fije en lugares tan comunes que de otra forma pasarían desapercibidos y piense en lo que realmente significan (E1 País, 31-7-2013: 36)

Será a comienzos de la década de 1960 cuando, a la visión objetiva de los técnicos, y subjetiva de los artistas, se sume la mirada antropológica de la imagen de la ciudad por quienes la usan, los ciudadanos y sus mapas mentales, que ponen de manifiesto las formas de percibir, apropiarse y sentir los espacios urbanos. Fue Kevin Lynch, desde el Instituto Tecnológico de Massachusetts, con su obra La imagen de la ciudad (1960) el primero en reaccionar al desinterés por lo social y las raíces del lugar que habían caracterizado los proyectos urbanísticos de esos años, el denominado "determinismo físico" que entendía que la forma física apenas tenía incidencia en la forma social de nuestro entorno, y por tanto generan espacios físicos que no 
crean ambiente urbano y tienen un impacto negativo en la experiencia de la vida de las gentes. Frente a esta actitud, Lynch desarrolla investigaciones sobre la forma y el diseño de la ciudad centrando su interés en la interacción entre el espacio físico y su uso humano, planteando el novedoso problema de "dar forma visual a la ciudad", como consecuencia de ser ésta percibida por los ciudadanos. Le preocupaba la interacción entre el espacio físico y su uso humano, la manera en que experimentaba su entorno el ciudadano, qué valoraba y cómo la forma urbana conformaba su vida y sus actividades. Cómo la gente percibe y organiza su entorno.

El argumento de Lynch se apoya en la defensa del diseño de la ciudad no sólo como ordenador u organizador físico de las cosas para satisfacer las necesidades actuales, sino que también tiene que ver con los valores y derechos humanos fundamentales: justicia, libertad, control, aprendizaje, accesos, dignidad y creatividad. La imagen del ambiente, el espacio usado por el ciudadano, tiene para él tres elementos de análisis: identidad, estructura y significado. Una imagen eficaz requiere, en primer término, la identificación de un objeto: identidad. En segundo término la imagen debe incluir una relación espacial del objeto con el observador y con otros objetos: estructura. Por último este objeto debe tener un cierto significado práctico o emotivo para el espectador.

Los elementos que configuran la imagen de la ciudad a partir de su forma física, y que requieren un análisis conjunto, los reduce a cinco: sendas, bordes, barrios, nodos e hitos (Lynch, 1974). Las sendas son los caminos por los que el observador se mueve, son los elementos predominantes y organizadores de su imagen de la ciudad, esto es, calles, paseos, canales y vías de ferrocarril. Los bordes son líneas de demarcación, fronteras o soluciones de continuidad. No se usan como las sendas, ya que son referencias laterales, pero sirven para mantener la cohesión de zonas enteras. Los barrios son áreas de dimensión mediana, caracterizadas por su homogeneidad, donde el observador "entra", identificables desde el interior y utilizables desde el exterior como referencia. Los nodos son focos o puntos estratégicos de una ciudad, de cruce o convergencia de sendas de uso intensivo, y puntos de partida o meta en los movimientos del observador. Por último, los hitos son mojones, señales, símbolos que establecen una relación visual o semántica y sirven de orientación y localización radial. Pueden tener valor general y amplio, o local y limitado. Son puntos destacados en el plano que aluden a edificios, monumentos o accidentes geográficos. Para Lynch la ciudad es un mundo artificial, en el mejor sentido del término, hecho con arte y modelado con objetivos humanos. Sobre ella podemos aplicar el análisis de la morfología urbana a partir de estos elementos configuradores, y así recordaremos la forma urbana con sus áreas diferenciadas, las actividades jerarquizadas, las vías principales, las centralidades y las edificaciones más representativas. Lynch describe una imagen de la ciudad que nos permite orientarnos para circular mejor por ella y acceder con facilidad y seguridad a nuestros destinos. A través de los nodos, sendas, hitos, bordes y barrios construimos nuestra memoria urbana, recordamos partes de una ciudad y establecemos referentes más permanentes. De esta manera, afirma, se comienzan a crear lazos de identidad entre el espacio y los seres que lo habitan. 
Esta idea representa la esencia del concepto de mapa mental, concebido como una construcción abstracta, que habla de las estructuras de percepción y pensamiento que le permiten al individuo ubicarse dentro del espacio; un modo de adquisición, almacenamiento, decodificación y utilización de la información, para la comprensión y uso del ambiente en el que habita. Es una representación simbólica que surge de la experiencia visual simplificada en un esbozo mental.

\section{Conclusión}

Siguiendo los planteamientos de Michel Baudson (Dethier, 1994: 362) se puede afirmar que el intercambio entre la creatividad artística y la ciudad aparece desde mediados del siglo XX en obras e intervenciones artísticas que se erigen más como testimonios y actores que en simples visionarios: perciben y representan la situación urbana en su funcionamiento, su disfuncionamiento y su caos, o promueven, desde lo imaginario a lo real, las potencialidades de la confrontación con la diferencia.

Las ciudades no son solamente ámbitos físicos dominados por la materialidad de sus calles, sus parques, sus edificios y sus señales. Las ciudades se configuran también como imágenes (García Canclini, 1997), y éstas pueden ser tanto las de los planos de los arquitectos que las ordenan, como las recreadas por artistas plásticos, literatos, músicos, cineastas o comunicadores sociales. Al final, la ciudad se vuelve densa, cargada de fantasías heterogéneas, de ficciones individuales y colectivas.

La historia de la ciudad moderna a través de sus artistas y sus arquitectos es la historia de un diálogo, a menudo de sordos, entre los artistas que revelan las contradicciones de la ciudad moderna y señalan aquellos árboles que el bosque de la ciudad racional perfecta puede hacer olvidar, y los urbanistas, dispuestos a tomar la ciudad como un espacio de experimentación y conquista para moldearlo a su imagen y semejanza. Es en los puntos de contacto entre estas dos actitudes (la imaginación y la experiencia del artista y la invención y la representación del urbanista) donde emerge el complejo concepto de ciudad (Dethier, 1994: 12).

\section{Bibliografía}

AAVV. (1990). L'art et la ville. Urbanisme et art contemporain. Ginebra: Skira. AAVV. (1995). L'art renouvelle la ville, urbanisme et art contemporain. Paris: Musèe National des Monuments Francaises.

ARGAN, G.C. (1984). Historia del arte como historia de la ciudad. Barcelona: Laia. BADENES, D. (2007). "Comunicación y ciudad: líneas de investigación y encuentros con la historia cultural urbana". Question. vol. 1, $\mathrm{n}^{\mathrm{o}}$ 14, otoño. Argentina: Universidad Nacional de La Plata. 
BLAZWICK, I (2001). Century City. Art and Culture in the Modern Metropolis. London: Tate Modern.

CACCIARI, M. (1973). Metropolis. Saggi sulla grande città di Sombart, Endell, Schffler e Simmel. Roma: Officina Edizioni.

DETHIER, J.; GUIHEUX, A. (1994). Visiones urbanas. Europa 1870-1993. La ciudad del artista. La ciudad del arquitecto. Barcelona: Electa.

GARCÍA CANCLINI, N. (1997). Imaginarios urbanos. Buenos Aires: Eudeba.

GARCÍA CANCLINI, N. (2001). Culturas hibridas: estrategias para entrar y salir de la modernidad. Buenos Aires: Paidos.

GONZÁLEZ, A.; MARCHÁN, S.; CALVO, F. (1999). Escritos de arte de vanguardia (1900-1945). Madrid: Istmo.

GORELIK, A. (2004). Miradas sobre Buenos Aires. Historia cultural y crítica urbana. Buenos Aires: Siglo XXI.

HAYDEN, D. (1995). The power of place. Urban landscape as public history. Cambridge Mass. - London: The MIT Press.

LAYUNO ROSAS, A. (2003). "Museos de arte contemporáneo y ciudad. Los límites del objeto arquitectónico". En LORENTE, J.P. (dir) Museología crítica y arte contemporáneo. Zaragoza: Prensas Universitarias, p. 109-123.

LAYUNO ROSAS, A. (2004). Museos de arte contemporáneo en España. Del templo de las artes a la arquitectura como arte. Gijón: Trea.

LORENTE, J.P. (1997). Espacios de arte contemporáneo generadores de revitalización urbana. Zaragoza: Universidad de Zaragoza.

LORENTE, J.P. (1998). Cathedrals of urban modernity. The first museums of contemporary art 1800-1930. Aldershot: Ashgate International.

LYNCH, K. (1974). La imagen de la ciudad. Buenos Aires: Infinito.

MADERUELO, J. (1990). El espacio raptado. Interferencias entre arquitectura y escultura. Madrid: Mondadori.

MADERUELO, J. (1994). Arte Público. Huesca: Diputación de Huesca.

MADERUELO, J. (2000). Arte público: naturaleza y ciudad. Lanzarote: Fundación César Manrique.

MADRAZO, L. (2009). Imágenes de la ciudad contemporánea. Barcelona. Reflexiones. Barcelona: Publisher.

MARCHÁN, S. (1986). Contaminaciones figurativas. Imágenes de la arquitectura y la ciudad como figuras de lo moderno. Madrid: Alianza.

MARTÍN BARBERO, J. (1994). Mediaciones urbanas y nuevos escenarios de comunicación. Caracas: Fundarte.

MARTÍN BARBERO, J. (2010). De los medios a las mediaciones. Comunicación, cultura y hegemonía. Madrid: Anthropos.

MOYA PELLITERO, A. (2011). La percepción del paisaje urbano. Madrid: Biblioteca Nueva.

MUMFORD, L. (1966). La ciudad en la historia: sus origenes, transformaciones y perspectivas. Buenos Aires: Infinito.

PIZZA, A; PLA, M. (2002). Viena-Berlín. Teoría, arte y arquitectura entre los siglos $X I X$ y XX. Barcelona: Universitat Politecnica Catalunya. 
RAMÍREZ, J.A. (1988). Construcciones ilusorias. Arquitecturas descritas, arquitecturas pintadas. Madrid: Alianza.

ZUKIN, S. (1995). The Cultures of Cities. Cambridge MA: Blackwell.

ZUKIN, S. (2000). The Cultural Industry: the arts in urban regeneration. Aldershot: Ashgate International.

\section{Notas}

1. Este artículo se enmarca dentro del proyecto de investigación Arquitectura, urbanismo y representación en la construcción de la imagen de los barrios artísticos (ref. HAR2012-38899-C02-02) Ministerio de Economía y Competitividad. Convocatoria 2012. Plan Nacional I+D+i. Subprograma de Proyectos de Investigación Fundamental No Orientada.

\section{El autor}

Miguel Ángel Chaves Martín es profesor titular de Arte Contemporáneo y Comunicación Audiovisual en la Universidad Complutense de Madrid. Director del grupo de investigación UCM Consolidado "Arte, Arquitectura y Comunicación en la Ciudad Contemporánea" (ref. 930216), actualmente coordina como investigador principal el proyecto $\mathrm{I}+\mathrm{D}+\mathrm{i}$ "Arquitectura, urbanismo y representación en la construcción de la imagen de los barrios artísticos". Sus líneas de investigación se centran en la arquitectura y el urbanismo contemporáneos, estudios de iconografía y construcción del paisaje urbano, conservación del patrimonio monumental, y teoría y crítica del arte contemporáneo. 